\title{
Prevalence and Correlates of Low Back Pain in Primary Care: What Are the Contributing Factors in a Rapidly Developing Country
}

\author{
Abdulbari Bener ${ }^{1,2}$, Elnour Elnaeim Dafeeah ${ }^{3}$, Khalid Alnaqbi ${ }^{4}$ \\ ${ }^{I}$ Department of Medical Statistics and Epidemiology, Hamad Medical Corporation and Department of Public Health, \\ Weill Cornell Medical College, Doha, Qatar \\ ${ }^{2}$ Department of Evidence for Population Health Unit, School of Epidemiology and Health Sciences, The University of Manchester, Manchester, UK \\ ${ }^{3}$ Department of Psychiatry, Rumeilah Hospital, Hamad Medical Corporation, Doha, Qatar \\ ${ }^{4}$ Institute of Medical Science, University of Toronto, Clinical Research Rheumatology and Spondyloarthritis Program, \\ Arthritis Centre of Excellence, Toronto Western Hospital, Toronto, ON, Canada
}

Study Design: Cross-sectional.

Purpose: The purpose of the study was to determine the prevalence of low back pain (LBP) in the primary care setting with emphasis on the socio-demographic contributing factors and impact of LBP on lifestyle habits.

Overview of Literature: LBP is one of the most common medical conditions seen in the Primary Health Care Clinic.

Methods: A representative sample of 2,600 patients were approached and 1,829 subjects agreed to participate in this study (70.0\%). Data on socio-demographic characteristics, life style habits and type of treatment were collected through a questionnaire.

Results: The prevalence of LBP in the study sample was 56.5\% (95\% confidence interval, 54.2-58.8). LBP was more prevalent among women (53.9\%) compared to men (46.1\%). There was significant difference between male and female patients of LBP in terms of ethnicity $(p<0.001)$, marital status $(p=0.010)$, occupation $(p<0.001)$, monthly household income $(p=0.004)$, and cigarette/sheesha smokers $(p<0.001)$. The percentages of different aspects of functional disabilities were statistically significantly higher among females compared to male patients with LBP. Almost a quarter of female patients with LBP (26\%) and $18 \%$ male patients with LBP reported pain in the arms and legs ( $p=0.002)$. In addition, gastrointestinal complaints such as abdominal pain and food intolerance were significantly higher among female patients with LBP as compared to males ( $31 \%$ vs. $24.6 \%, p=0.018$; and $25 \%$ vs. $18 \%, p=0.008$, respectively). Complaints about headache and fainting were also significantly higher among female patients as compared to male LBP patients ( $43 \%$ vs. $36 \%, p=0.029$; and $26 \%$ vs. $20 \%, p=0.016$, respectively). The multivariate logistic regression revealed that being female, prolonged standing, prolonged sitting, heavy weight lifting, weakness in the legs, regular exercise, and cigarette/sheesh a smoking had a significant effect on the presence of LBP.

Conclusions: LBP is highly prevalent among both genders and in older age. Also, weakness in the legs, smoking, prolonged standing and sitting had a significant effect on LBP. Furthermore, the current study findings support the fact that LBP continues to be an important clinical, social and economic, burden and a public health problem affecting the population of the entire world.

Keywords: Epidemiology; Low back pain; Roland-Morris disability; Risk factors; Life-style habits; Primary health care

Received Jan 13, 2013; Revised Apr 15, 2013; Accepted Jul 4, 2013

Corresponding author: Abdulbari Bener

Department of Medical Statistics and Epidemiology, Hamad Medical Corporation and Department of Public Health,

Weill Cornell Medical College, PO Box 3050, Doha, Qatars

Tel: +974-4439-3765, Fax: +974-4439-3769, E-mail: abener@hmc.org.qa 


\section{Introduction}

Chronic low back pain (LBP) is a serious medical and social problem, and one of the most common causes of disability, and nearly everyone at some point suffers from LBP that interferes with work and recreational activities [1,2]. Nearly everyone gets LBP at least once in their lifetime, making the effective treatment of this common complaint become of widespread interest [1]. It is the most common reason for middle-aged people to visit their family doctor. In a few cases, there is a serious cause, but generally, it is not possible to identify a specific cause of the pain [3-5]. LBP is well documented to be an extremely common health problem; however, its burden is often considered trivial [3-11]. It is the leading cause of activity limitation and work absence and it causes enormous economic burden on individuals, families, communities, industry and governments [3]. In the past, it was documented that LBP is a common complaint in general practice in primary care settings [1-9]. The exact cause of pain cannot be identified in most instances. Recent studies continue to confirm that LBP is a common disorder in western and developing nations [3]. It is estimated [5] that about $80 \%$ of all populations will experience LBP at some period during their lifetime, and about $18 \%$ of the population experience LBP at any given moment each year, and $7 \%$ of the adult population consult their general practice with symptoms. The intercultural differences between nationalities in pain perception or pain reporting may be an explanation for the variation in prevalence rates among countries [1-19]. It was largely thought of as a problem confined to western countries, but at the moment, due to the extensive amount of research on this problem, it has been demonstrated that LBP is also a major problem in low and middle income countries [1-7,10-12].

Bener et al. [10-12] reported in their previous study that LBP can have a substantial negative impact on the quality of life. Risk factors of LBP are multi-factorial, and include physical factors, social demographic characteristics, habits and psychological factors. The aim of the study was to determine the prevalence of LBP in the primary care setting, with emphasis on the socio-demographic contributing factors and the impact of LBP on lifestyle habits.

\section{Materials and Methods}

This is a cross sectional study and the study included subjects aged 15 to 65 years who attended primary health care centers throughout Qatar. The sample size was determined with the prior knowledge that the prevalence of LBP in the State of Qatar is similar to that in a neighboring country. A minimum sample size of 2,600 subjects aged between 15 and 60 years was calculated based on the prevalence of LBP in the United Arab Emirates [1012 ] and other places, reported to be over $50 \%$, with an allowed bound of $2.0 \%$ error of estimation and $99 \%$ confidence level. A representative sample of 2,600 patients were approached and 1,829 subjects agreed to participate in this study $(70.0 \%)$. Primary health care centers are frequented by all levels of the general population as a gateway to specialist care. In order to secure a representative sample of the study population, the sampling plan was stratified with proportional allocation according to the stratum size of the Primary Health Care Clinics. The study was conducted among people who were visiting 13 health centers: 10 centers from an urban area and 3 centers from a semi-urban area, as a representative sample of the community. Data collection took place from March to December, 2012. Qualified nurses were trained to interview the patients and complete the questionnaires. The survey instrument was tested on 100 patients who visited the health centers, and thus the questionnaire was validated. The study excluded patients aged below 15 years and above 65 years, patients with any cognitive or physical impairment and those who refused to give consent to take part in the study.

\section{Roland-Morris disability questionnaire}

The Roland-Morris disability questionnaire (RDQ) is constructed by choosing statements from the sickness impact profile, which is a 136-item health status measure covering a range of aspects of daily living about physical and mental functioning [8,9]. This is a modified 24-item version of the Roland-Morris Scale for evaluating back disability. The scale consists of 21 yes/no items related specifically to physical functions to specifically assess the disability from LBP. The physical functions considered include walking, bending over, sitting, lying down, dressing, sleeping, self-care and daily activities. Patients are asked whether the statements apply to them that day (i.e., the last 24 hours). In the scale, one point is given for each item. The RDQ score can be obtained by adding up the number of items checked. The final score ranges from 0 (no 
disability) to 21 (severe disability). The questionnaire is self-administered by the patient, it can be completed in a maximum of 5 minutes, and an unweighted score can be calculated in less than 1 minute.

The data was collected through a validated self-administered questionnaire with the help of qualified nurses. The questionnaire included socio-demographic details of the patients, associated factors like the physical life style pattern, triggering factors and type of treatment taken by patients for relief, for the data collection. Approval was obtained from the Hamad Medical Corporation Institutional Review Board for conducting this research in Qatar.

\section{Statistical analysis}

The Statistical Package for Social Sciences (SPSS) was used for the statistical analysis. Student's $t$-test was used to ascertain the significance of differences between the mean values of two continuous variables, and the MannWhitney test was performed for the nonparametric test. Chi-square analysis was performed to test for differences in the proportions of categorical variables between two or more groups. Stepwise logistic regression analysis was used to predict potential confounders and to rank the risk factors (determinants) for LBP (1=LBP, $2=$ without LBP); independent variables were a combination of continuous and categorical variables. The cut-off value for significance was considered to be $p<0.05$.

\section{Results}

Table 1 shows a comparison of socio-demographic and other characteristics between males and females with LBP. Among the subjects with LBP, $48 \%$ were males and $52 \%$ were females. There was a significant difference between male and female patients of LBP in terms of ethnicity $(p<0.001)$, marital status ( $p=0.010)$, occupation $(p<0.001)$, monthly household income $(p=0.004)$ and cigarette/sheesha smoking $(p<0.001)$. Nearly all the LBP characteristics were more common among females than males, particularly pain with any weakness in the leg $(23 \%$ vs. $13.3 \%$; $p=0.025$ ), prolonged standing ( $49.5 \%$ vs. $39.9 \%$; $p=0.026$ ), prolonged sitting ( $45.4 \%$ vs. $38.1 \%$; $p=0.020$ ), and lifting heavy weights ( $41.8 \%$ vs. $36.3 \%$; $p<0.039$ ).

Table 2 provides a comparison of functional disability between male and female patients with LBP. The percent- ages of different aspects of functional disabilities were statistically significantly higher among females compared to male patients with LBP.

Table 3 shows lifetime prevalence of somatization symptoms between male and female patients with LBP. Almost a quarter of the female patients with LBP (26\%) and $18 \%$ of the male patients with LBP reported pain in the arms and legs $(p=0.002)$. In contrast, a significantly higher proportion of male patients with LBP as compared to females complained about shortness of breath $(26.2 \%$ vs. $20.4 \%$; $p=0.028)$ and palpitations $(25.2 \%$ vs. $18.6 \%$; $p=0.010$ ). In addition, gastrointestinal complaints such as abdominal pain and food intolerance were significantly higher among female patients with LBP as compared to male patients ( $31 \%$ vs. $24.6 \%, p=0.018$; and $25 \%$ vs. $18 \%$, $p=0.008$, respectively). Complaints about headache and fainting were also significantly higher among female patients as compared to male patients with LBP (43\% vs. $36 \%, p=0.029$; and $26 \%$ vs. $20 \%, p=0.016$, respectively).

Table 4 depicts the multivariable logistic regression analysis for the predictors of LBP. Being female (odds ratio [OR], 1.41; 95\% confidence interval [CI], 1.14-1.74; $p=0.001$ ), having a lifestyle or job that demanded prolonged standing (OR, 1.70; 95\% CI, 1.34-2.16; $p<0.001$ ), prolonged sitting (OR, 2.13; 95\% CI, 1.62-2.80; $p<0.001$ ), heavy weight lifting (OR, 2.36; 95\% CI, 1.76-3.17; $p<0.001)$, weakness in the leg (OR, 1.52; 95\% CI, 1.082.29; $\mathrm{p}=0.049)$, body mass index (BMI) more than 30 (OR, 2.31; 95\% CI, 1.85-2.88; $p<0.001)$ and cigarette/sheesha smoking (OR, 2.44; 95\% CI, 2.20-2.71; $p<0.001$ ) were independently associated with LBP among the participants in Qatar.

Fig. 1 examines the treatment taken by the studied LBP patients for relief. Most of them had bed rest (67.2\%) followed by warm compression (47.6\%), physiotherapy (47.5\%), regular exercise (40\%), and back plasters (33.5\%).

\section{Discussion}

This is the first study involving a primary care-based survey in Qatar. LBP is a multi-factorial disorder with many possible aetiologies. The present epidemiologic study of LBP analyzed various risk factors of LBP in a general population of Qatar. LBP is the most common health problem. Many factors have been demonstrated to be fundamental risk factors of LBP such as BMI, age, gender, 
Table 1. Socio demographic character of the low back pain patients according to gender $(n=1,829)$

\begin{tabular}{|c|c|c|c|}
\hline \multirow{2}{*}{ Variable } & \multicolumn{2}{|c|}{ Low back pain } & \multirow{2}{*}{$p$-value } \\
\hline & 496 of 934 men reporting & 538 of 895 women reporting & \\
\hline Age group (yr) & & & 0.168 \\
\hline$<35$ & $63(12.7)$ & $86(16.0)$ & \\
\hline $35-44$ & $123(24.8)$ & $111(20.6)$ & \\
\hline $45-55$ & $171(34.5)$ & $174(32.3)$ & \\
\hline$>55$ & $139(28.0)$ & $167(31.0)$ & \\
\hline $\mathrm{BMI}$ group $\left(\mathrm{kg} / \mathrm{m}^{2}\right)$ & & & 0.022 \\
\hline$<24.99$ & $151(30.4)$ & $134(29.9)$ & \\
\hline $25-30$ & $231(46.6)$ & $243(45.2)$ & \\
\hline$>30$ & $114(23.0)$ & $161(29.9)$ & \\
\hline Nationality & & & $<0.001$ \\
\hline Qatari & $192(38.7)$ & $341(63.4)$ & \\
\hline Non-qatari & $304(61.3)$ & $197(36.6)$ & \\
\hline Marital status & & & 0.010 \\
\hline Single & $31(6.3)$ & $52(9.7)$ & \\
\hline Married & $445(89.7)$ & 448 (83.3) & \\
\hline Widow & $20(4.0)$ & $38(7.1)$ & \\
\hline Level of education & & & 0.182 \\
\hline Illiterate & $72(14.5)$ & $79(14.7)$ & \\
\hline Elementary & $94(19.0)$ & $115(21.4)$ & \\
\hline Intermediate & $119(24.0)$ & $104(19.3)$ & \\
\hline Secondary & $107(21.6)$ & $140(26.0)$ & \\
\hline University & $104(21.0)$ & $100(18.6)$ & \\
\hline Occupation & & & $<0.001$ \\
\hline House wife/not working & $52(10.5)$ & $287(53.3)$ & \\
\hline Sedentary \& professional & $106(21.4)$ & $64(11.9)$ & \\
\hline Clerical & $234(47.2)$ & $117(21.7)$ & \\
\hline Businessman & $64(12.9)$ & $35(6.5)$ & \\
\hline Arm/police & $40(8.1)$ & $35(6.5)$ & \\
\hline Monthly household income & & & 0.004 \\
\hline Less than $\$ 2,000$ & $41(8.3)$ & $31(5.8)$ & \\
\hline$\$ 2,000-\$ 3,999$ & $144(29.0)$ & $212(39.4)$ & \\
\hline$\$ 4,000-\$ 5,999$ & $186(37.5)$ & $180(33.5)$ & \\
\hline$>\$ 6,000$ & $125(25.2)$ & $115(21.4)$ & \\
\hline Smoking habit & & & 0.014 \\
\hline Cigarette smoking & $58(11.7)$ & $37(6.9)$ & \\
\hline Sheesha smoking & $49(9.9)$ & $69(12.8)$ & \\
\hline No smoking & $389(78.4)$ & 432 (80.3) & \\
\hline \multicolumn{4}{|l|}{ LBP exacerbation by } \\
\hline Prolong standing (1 hr or more) & $198(39.9)$ & $259(49.5)$ & 0.026 \\
\hline Prolong sitting ( $1 / 2 \mathrm{hr}$ or more) & $189(38.1)$ & $244(45.4)$ & 0.020 \\
\hline
\end{tabular}


Table 1. Continued

\begin{tabular}{lcccc}
\multirow{2}{*}{ Variable } & \multicolumn{3}{c}{ Low back pain } & \multicolumn{1}{c}{$p$-value } \\
\cline { 2 - 3 } & 496 of 934 men reporting & 538 of 895 women reporting & 0.039 \\
\hline Lifting heavy weights & $180(36.3)$ & $225(41.8)$ & 0.008 \\
\hline After exercise & $91(18.3)$ & $136(25.3)$ & $<3(17.3)$ & $<0.001$ \\
\hline Coughing/sneezing/straining & $42(8.5)$ & $154(28.6)$ & $<0.001$ \\
\hline Turning position & $92(18.5)$ & $124(23.6)$ & 0.025 \\
\hline Weakness in legs & $66(13.3)$ & & \\
\hline
\end{tabular}

Values are presented as number (\%). LBP, Low back pain.

Table 2. Functional disability in patients with recent onset of low back pain by gender ( $n=1,829)$

\begin{tabular}{|c|c|c|c|}
\hline \multirow[b]{2}{*}{ Functional disability } & \multicolumn{2}{|c|}{ Low back pain } & \multirow[b]{2}{*}{$p$-value } \\
\hline & $\begin{array}{c}496 \text { of } 934 \text { men } \\
\text { reporting }\end{array}$ & $\begin{array}{l}538 \text { of } 895 \text { women } \\
\text { reporting }\end{array}$ & \\
\hline 1. I stay at home most of the time. & $203(21.7)$ & $287(32.1)$ & $<0.001$ \\
\hline 2. I change position frequently to make my back or leg comfortable. & $456(48.8)$ & $497(55.5)$ & 0.004 \\
\hline 3. I walk more slowly than usual because of back or leg pain. & $365(39.1)$ & $402(44.9)$ & 0.012 \\
\hline 4. I am not doing any of the jobs that I usually do. & $278(29.8)$ & $324(36.2)$ & 0.004 \\
\hline 5. Because of my back problem, I use handrail to get upstairs. & $288(30.8)$ & $330(36.9)$ & 0.007 \\
\hline 6. I have to hold onto something to get out of an easy chair. & $321(34.4)$ & $355(39.7)$ & 0.020 \\
\hline 7. I get dress more slowly than usual. & $246(26.3)$ & $316(35.3)$ & $<0.001$ \\
\hline 8. I stand for only short periods of time & $412(44.1)$ & 402 (44.9) & 0.742 \\
\hline 9. I try not to bend or kneel down. & $303(61.1)$ & $441(49.3)$ & 0.722 \\
\hline 10. I find it difficult to turn over in bed. & 306 (32.8) & $369(41.2)$ & $<0.001$ \\
\hline 11. My back or leg is painful almost all the time. & $228(24.4)$ & $311(34.7)$ & $<0.001$ \\
\hline 12. I walk only short distance. & $300(32.1)$ & $368(41.1)$ & $<0.001$ \\
\hline 13. I sleep less well. & $403(43.1)$ & $451(50.4)$ & 0.002 \\
\hline 14. I avoid heavy jobs around the house or work. & $472(50.5)$ & $413(46.1)$ & 0.061 \\
\hline 15. I am more irritable \& bad tempered with people. & $340(36.4)$ & $222(24.8)$ & $<0.001$ \\
\hline 16. I go upstairs more slowly than usual. & $285(30.5)$ & $241(26.9)$ & 0.088 \\
\hline 17. I stay in bed most of time. & $329(35.3)$ & $282(31.5)$ & 0.092 \\
\hline 18. My sexual activity decreased. & $235(25.2)$ & $196(21.9)$ & 0.099 \\
\hline 19. Rubbing or holding areas of hurt or any uncomfortable. & $428(45.8)$ & $348(38.9)$ & 0.003 \\
\hline 20. I am doing less work than I would usually do. & $369(39.5)$ & $321(35.9)$ & 0.111 \\
\hline 21. I often express concern to other people due my health. & $325(34.9)$ & $262(29.3)$ & 0.007 \\
\hline
\end{tabular}

Values are presented as number (\%).

occupation, socio-economic factors and other factors [115]. The study focused on risk factors for LBP, attempting to analyse the socio-demographic characteristics, and individual and physical factors such as gender, age, nationality, BMI, lifestyle habits, physical straining, heavy lifting and postural stress. In the current study, the prevalence of LBP was 56.5 (95\% CI, 54.2-58.8), which is in line with the rates observed in Denmark [13] (56\%), Africa [14] (62\%), and China [15] (64\%). The prevalence rates observed in developed countries like Australia (25.6\%) [16], Canada (28.7\%) [17], the United Kingdom (36.1\%) [18], and Sweden (39.2\%) [19] were reasonably lower than the prevalence rate of this study. Fig. 2 compares the prevalence rate of LBP in the general populations of developed 
Table 3. Lifetime prevalence of somatization symptoms of low back pian patients by Gender

\begin{tabular}{|c|c|c|c|}
\hline \multirow{2}{*}{ Symptom } & \multicolumn{2}{|c|}{ Low back pain } & \multirow{2}{*}{$p$-value } \\
\hline & 496 of 934 men reporting & 538 of 895 women reporting & \\
\hline \multicolumn{4}{|l|}{ Pain } \\
\hline Pain & $179(36.1)$ & $217(40.3)$ & 0.161 \\
\hline Joint pain & 92 (18.5) & $122(22.7)$ & 0.102 \\
\hline Pain in arms and legs & $88(17.7)$ & $139(25.8)$ & 0.002 \\
\hline Pain anywhere else & $107(21.6)$ & $127(23.6)$ & 0.435 \\
\hline \multicolumn{4}{|l|}{ Cardiopulmonary } \\
\hline Chest pains & $131(26.4)$ & $146(27.1)$ & 0.792 \\
\hline Shortness of breath & $130(26.2)$ & $110(20.4)$ & 0.028 \\
\hline Palpitations & $125(25.2)$ & $100(18.6)$ & 0.010 \\
\hline Dizziness & $118(23.8)$ & $108(20.1)$ & 0.149 \\
\hline \multicolumn{4}{|l|}{ Gastrointestinal } \\
\hline Abdominal pain & $122(24.6)$ & $168(31.2)$ & 0.018 \\
\hline Nausea & $79(15.9)$ & $104(19.3)$ & 0.152 \\
\hline Gas or indigestion & $79(15.9)$ & $79(14.7)$ & 0.579 \\
\hline Diarrhea & $179(36.1)$ & $206(38.3)$ & 0.464 \\
\hline Intolerance & $90(18.1)$ & $134(24.9)$ & 0.008 \\
\hline Vomiting & $115(23.2)$ & $142(26.4)$ & 0.233 \\
\hline \multicolumn{4}{|l|}{ Pseudoneurologic } \\
\hline Trouble in walking & $75(15.1)$ & $106(19.7)$ & 0.053 \\
\hline Unconscious & $53(10.7)$ & $71(13.2)$ & 0.214 \\
\hline Weakness & $104(21.0)$ & $83(15.4)$ & 0.021 \\
\hline Blurred vision & $113(22.8)$ & $147(27.3)$ & 0.093 \\
\hline \multicolumn{4}{|l|}{ Lifestyle } \\
\hline Feeling tired or having low energy & $128(25.8)$ & $157(29.2)$ & 0.225 \\
\hline Trouble sleeping & $122(24.6)$ & $172(32.0)$ & 0.017 \\
\hline Fainting & $97(19.6)$ & $139(25.8)$ & 0.016 \\
\hline Headache & $180(36.3)$ & 231 (42.9) & 0.029 \\
\hline
\end{tabular}

Values are presented as number (\%).

Table 4. Stepwise logistic regression analysis for the predictors of low back pain

\begin{tabular}{lcc} 
Variables & Adjusted odds ratio (95\% confidence intervals) & $p$-value \\
Cigarette/sheesha smoking & $2.44(2.20-2.71)$ & $<0.001$ \\
Heavy weight lifting & $2.36(1.76-3.17)$ & $<0.001$ \\
\hline Body mass index $\left(>30 \mathrm{~kg} / \mathrm{m}^{2}\right)$ & $2.31(1.85-2.88)$ & $<0.001$ \\
Prolong sitting $(\geq 1 / 2 \mathrm{hr})$ & $2.13(1.62-2.80)$ & $<0.001$ \\
Prolong standing $(\geq 1 \mathrm{hr})$ & $1.70(1.34-2.16)$ & $<0.001$ \\
Weakness in the leg & $1.52(1.08-2.29)$ & 0.049 \\
Gender (female) & $1.41(1.14-1.74)$ & $<0.001$ \\
\hline
\end{tabular}




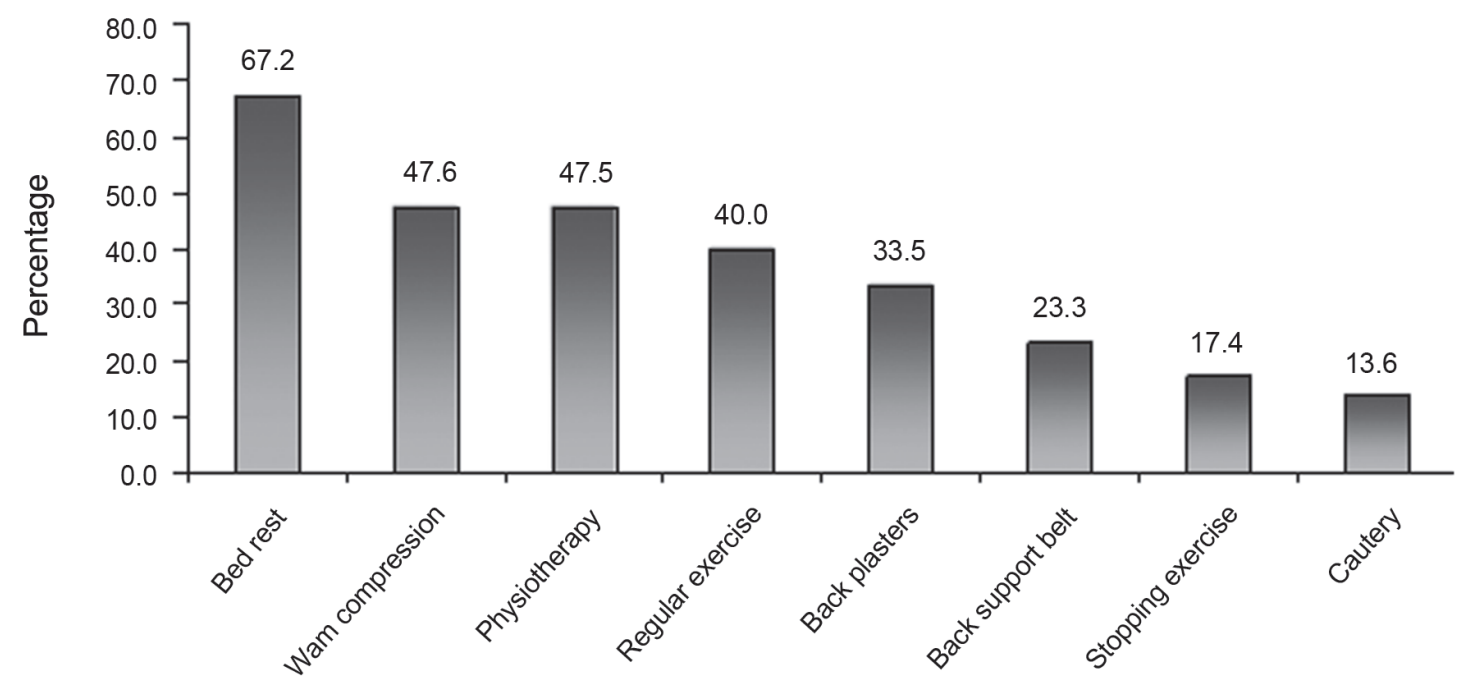

Fig. 1. Treatment taken for relief by studied low back pain patients $(n=1,034)$.

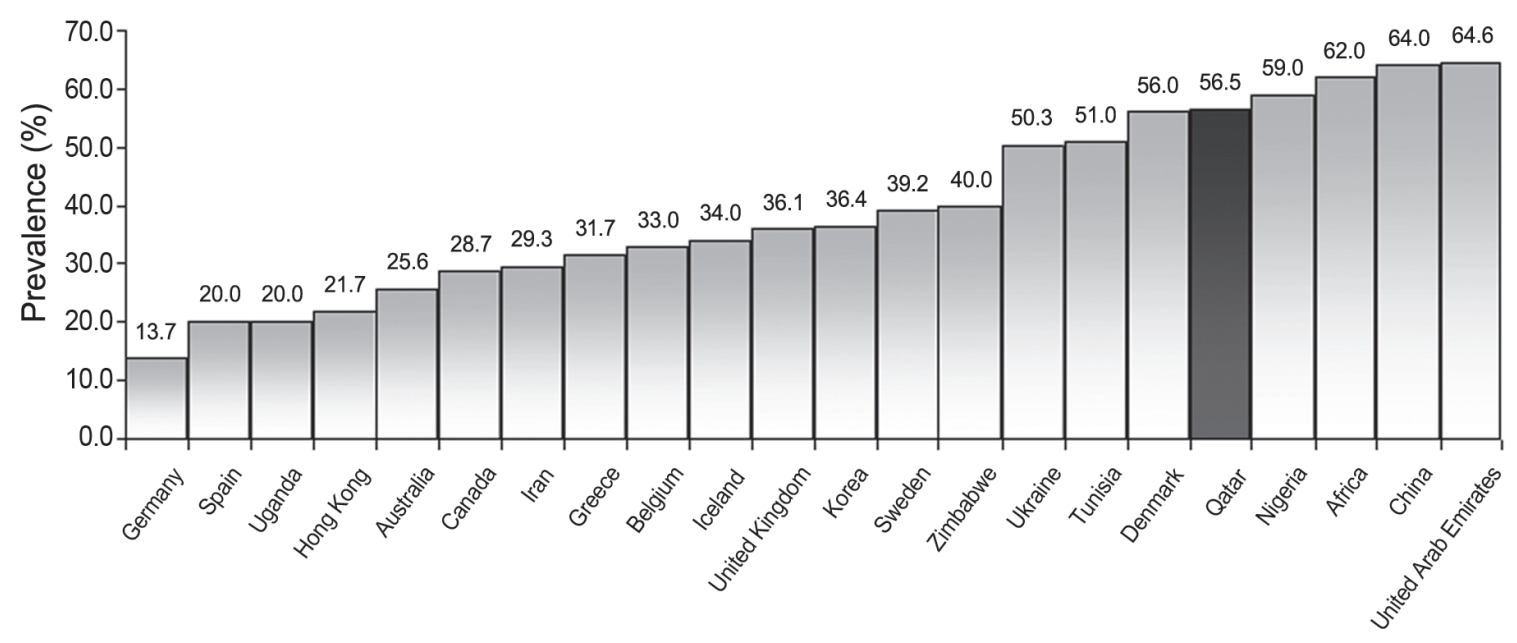

Fig. 2. Global comparison of prevalence rates of low back pain in the general populations of developed and developing countries.

and developing countries. The prevalence rate of LBP in Qatar was much higher than the rate observed in developed countries like Canada (28.7\%), the United Kingdom (36.1\%), and Sweden (39.2\%), and was very close to the rate in Africa (62\%) and China (64\%).

Previous reported studies in the UK [18] showed that the presence of LBP was associated with sociodemographic factors, among them sex, age, education level, smoking, and occupation. The present study also disclosed significant correlations between the frequency of LBP and socio-demographic factors, which is in accordance with earlier observations [1-4,10-12,20-26].
It is possible that LBP is more likely to be reported by those with a lower economic index and lower educational qualifications [3]. Higher education and economic status may provide knowledge or resources that influences the incidence of LBP to be lower. The present study found that LBP was higher in females compared to males. This is consistent with the previously reported studies $[3,10-$ 13,22-24] that showed that LBP symptoms were consistently more common among females. Schneider et al. [13] and Hathorn et al. [24] stated that the risk of LBP is higher among females due to the stress of hormonal changes, gynaecological problems and childbirth. 
In the study sample, subjects with an educational level of high school graduation had a higher chance of developing LBP than those with college graduation. Low educational status, below the intermediate educational level, has been shown to be associated with an increased prevalence of LBP which is similar to the study findings of Kwon et al. [25]. Also, the majority of the LBP patients had clerical jobs. Among patients with LBP, more than half of the women (53.3\%) were housewives, while most of the men $(47.2 \%)$ had clerical jobs with a significant difference between both the genders in their occupations $(p<0.001)$. Economic status was very low in the studied LBP patients with a monthly income. This confirms the results of a study reported by Waddel [26] and others [3,10-12] that showed the prevalence of LBP may be slightly greater in those from a lower socioeconomic class.

Obesity behaved as an important predictor, in agreement with the findings in the literature $[3,10,11,20,22,27$, 28]. Shiri et al. [27] have reported that obesity is a risk factor for LBP in both cross-sectional and cohort studies. Biomechanics and metabolic factors have been suggested to explain this relation. Obesity may cause LBP through the metabolic syndrome, and it is also possible that obesity and LBP are linked more directly via inflammatory mechanisms [3]. Obesity has been shown as a risk factor for disc degeneration [1-3] and may increase the prevalence of LBP in this way. Because of a worldwide increase in the prevalence of obesity, it is reasonable to assume that the prevalence of back pain will continue to increase. Obesity and overweight status were significantly higher in men and women with LBP. Stepwise logistic regression revealed that obesity $\left(\mathrm{BMI}>30 \mathrm{~kg} / \mathrm{m}^{2}\right)$ was a strong contributing factor for LBP, which is in accordance with earlier studies [10-12,20,22,27,29] that showed that obesity or higher BMI was associated with an increased occurrence of LBP.

Life style habits have a great influence on LBP patients. It was reported [27-29] that factors such as heavy physical work, prolonged sitting or standing, bending, twisting, pulling and pushing have often been associated with LBP. This is consistent with previously reported studies [17,10-12].

In the present study, a smoking habit was significantly higher in LBP patients, with significant difference to healthy subjects, which is similar to a study $[3,10-12,20$ 22 ] that showed that smoking was found to increase the risk for LBP patients. The association between smoking and LBP may be explained by the analgesic properties of nicotine [3]. Our results showed that smoking was consistently associated with LBP [3,10-12,20-22]. This is consistent with the previously reported studies that revealed that smoking was a strong contributing factor for LBP.

This study has several important limitations. First, the replies to the questionnaires were patients' self-reports and therefore current episodes of LBP may not be accurately represented. To counteract this problem, professional nurses were given training on LBP before the data collection process and they conducted the face-to-face interviews for the data collection. Also, all efforts were made to achieve the best estimates of LBP including the current episodes. Second, elderly patients were intentionally excluded. Third, this dataset probably did not distinguish precisely between incident and prevalent cases of back pain. Therefore the factors found on logistic regression to be associated with LBP represent a combination of risk and prognostic factors.

This cross-sectional study showed that LBP is highly prevalent among both genders and in older age. Also, weakness in the legs, smoking, and prolonged standing and sitting had a significant effect on LBP to the point that it compromised patients' daily lives and work habits significantly. Furthermore, the current study's findings support the fact that LBP continues to be an important clinical, social and economic burden and a public health problem affecting the population of the entire world.

\section{Conflict of Interest}

No potential conflict of interest relevant to this article was reported.

\section{Acknowledgments}

This work was generously supported and funded by the Qatar Foundation, UREP Grant No. 11-074-3-015. The authors would like to thank Hamad Medical Corporation for their support and granting ethical approval (HMC RP\# 12061/12).

\section{References}

1. Foster NE. Barriers and progress in the treatment of low back pain. BMC Med 2011;9:108. 
2. Rapoport J, Jacobs P, Bell NR, Klarenbach S. Refining the measurement of the economic burden of chronic diseases in Canada. Chronic Dis Can 2004;25:13-21.

3. Biglarian A, Seifi B, Bakhshi E, et al. Low back pain prevalence and associated factors in Iranian population: findings from the national health survey. Pain Res Treat 2012;2012:653060.

4. Latza U, Kohlmann T, Deck R, Raspe H. Can health care utilization explain the association between socioeconomic status and back pain? Spine (Phila Pa 1976) 2004;29:1561-6.

5. Walker BF. The prevalence of low back pain: a systematic review of the literature from 1966 to 1998. J Spinal Disord 2000;13:205-17.

6. Lemeunier N, Leboeuf-Yde C, Gagey O. The natural course of low back pain: a systematic critical literature review. Chiropr Man Therap 2012;20:33.

7. Hart LG, Deyo RA, Cherkin DC. Physician office visits for low back pain. Frequency, clinical evaluation, and treatment patterns from a U.S. national survey. Spine (Phila Pa 1976) 1995;20:11-9.

8. Roland M, Fairbank J. The Roland-Morris Disability Questionnaire and the Oswestry Disability Questionnaire. Spine (Phila Pa 1976) 2000;25:3115-24.

9. Maaroufi H, Benbouazza K, Faik A, et al. Translation, adaptation, and validation of the Moroccan version of the Roland Morris Disability Questionnaire. Spine (Phila Pa 1976) 2007;32:1461-5.

10. Bener A, El-Rufaie OF, Siyam A, Abuzeid MSO, Toth F, Lovasz G. Epidemiology of low back pain in the United Arab Emirates. APLAR J Rheumatol 2004;7: 189-95.

11. Bener A, Alwash R, Gaber T, Lovasz G. Obesity and low back pain. Coll Antropol 2003;27:95-104.

12. Bener A, El-Rufaie OF, Kamran S, Georgievski AB, Farooq A, Rysavy M. Disability, depression and somatization in a low back pain population. APLAR J Rheumatol 2006;9:257-63.

13. Schneider S, Randoll D, Buchner M. Why do women have back pain more than men? A representative prevalence study in the federal republic of Germany. Clin J Pain 2006;22:738-47.

14. Louw QA, Morris LD, Grimmer-Somers K. The prevalence of low back pain in Africa: a systematic review. BMC Musculoskelet Disord 2007;8:105.

15. Hoy D, Toole MJ, Morgan D, Morgan C. Low back pain in rural Tibet. Lancet 2003;361:225-6.
16. Walker BF, Muller R, Grant WD. Low back pain in Australian adults. health provider utilization and care seeking. J Manipulative Physiol Ther 2004;27:327-35.

17. Cassidy JD, Carroll LJ, Cote P. The Saskatchewan health and back pain survey. The prevalence of low back pain and related disability in Saskatchewan adults. Spine (Phila Pa 1976) 1998;23:1860-6.

18. Raspe H, Matthis C, Croft P, O’Neill T; European Vertebral Osteoporosis Study Group. Variation in back pain between countries: the example of Britain and Germany. Spine (Phila Pa 1976) 2004;29:101721.

19. Andersson HI, Ejlertsson G, Leden I, Rosenberg C. Chronic pain in a geographically defined general population: studies of differences in age, gender, social class, and pain localization. Clin J Pain 1993;9:174-82.

20. Deyo RA, Bass JE. Lifestyle and low-back pain. The influence of smoking and obesity. Spine (Phila Pa 1976) 1989;14:501-6.

21. Leboeuf-Yde C. Smoking and low back pain. A systematic literature review of 41 journal articles reporting 47 epidemiologic studies. Spine (Phila Pa 1976) 1999;24:1463-70.

22. Kaila-Kangas L, Leino-Arjas P, Riihimaki H, Luukkonen R, Kirjonen J. Smoking and overweight as predictors of hospitalization for back disorders. Spine (Phila Pa 1976) 2003;28:1860-8.

23. Kopec JA, Sayre EC, Esdaile JM. Predictors of back pain in a general population cohort. Spine (Phila $\mathrm{Pa}$ 1976) 2004;29:70-7.

24. Hathorn DC, Carruth AK, Agosta LJ, Pryor SK. Selfreported back pain among farm women in southeast Louisiana. AAOHN J 2009;57:232-8.

25. Kwon MA, Shim WS, Kim MH, et al. A correlation between low back pain and associated factors: a study involving 772 patients who had undergone general physical examination. J Korean Med Sci 2006;21:1086-91.

26. Waddell G. The back pain revolution. Edinburgh: Churchill Livingston; 1998.

27. Shiri R, Karppinen J, Leino-Arjas P, Solovieva S, Viikari-Juntura E. The association between obesity and low back pain: a meta-analysis. Am J Epidemiol 2010;171:135-54.

28. Heuch I, Hagen K, Heuch I, Nygaard O, Zwart JA. The impact of body mass index on the prevalence 
of low back pain: the HUNT study. Spine (Phila Pa 1976) 2010;35:764-8.

29. Shiri R, Solovieva S, Husgafvel-Pursiainen K, et al. The association between obesity and the prevalence of low back pain in young adults: the Cardiovascular Risk in Young Finns Study. Am J Epidemiol 2008;167:1110-9. 